\title{
New drugs and new concerns: Gaining insight through Pharmacovigilance of direct acting Anti-Viral's in chronic HCV patients
}

\author{
Zahid Yasin Hashmi ${ }^{1}$, Muhammad Qasim Zia², Akram Bajwa3, \\ Maqsood Ahmed ${ }^{4}$, Naveed Anwer ${ }^{5}$, Mahwish Raza ${ }^{6}$, Jaffer Bin Baqar ${ }^{7}$
}

\section{ABSTRACT}

Objective: The study aimed to assess the safety profile of Direct Acting Anti-Viral's (DAAs) among patients with chronic Hepatitis C Virus (HCV).

Methods: This multicenter, analytical cross-sectional study was conducted in six gastroenterology and Hepatology centers including Liver Center Faisalabad, Allama Iqbal Medical Institute and Liver Center DHQ Hospital Sialkot, Isra Hospital Hyderabad, Allied Hospital Faisalabad and Rehman Medical Institute Peshawar, between May 2018 and May 2019. The data regarding patient demographics, treatment plan and the frequency of Adverse Events (AEs), and their severity was collected using a pre-designed questionnaire and analyzed through SPSS version 20.0.

Results: A total of $511 \mathrm{HCV}$ patients were enrolled, with an overall male majority. Around $66.3 \%$ patients experienced a total of 419 AEs, out of which 61 events were suspected from DAAs while remaining 317 events were associated with Ribavirin. Pyrexia (24.6\%) and fatigue (14.8\%) were the most commonly reported AEs among patients receiving DAAs. Factors such as Ribavirin-based treatments and the presence of Cirrhosis were more likely to promote AEs occurrence OR $[95 \% \mathrm{Cl}]$ i.e. $5.2(2.3-9.1)$ and $1.9(1.1-3.1)$ respectively $(\mathrm{p}<0.05)$.

Conclusion: It is concluded from the study results that DAAs have displayed promising outcomes due to the minimal and minor AEs reported.

KEYWORDS: Adverse Events, Chronic Hepatitis, Direct-Acting Antivirals.

How to cite this:

doi: https://doi.org/10.12669/pjms.37.2.3400

Hashmi ZY, Zia MQ, Bajwa A, Ahmed M, Anwer N, Raza M, et al. New drugs and new concerns: Gaining insight through Pharmacovigilance of direct acting Anti-Viral's in chronic HCV patients. Pak J Med Sci. 2021;37(2):299-304. doi: https://doi.org/10.12669/pjms.37.2.3400

This is an Open Access article distributed under the terms of the Creative Commons Attribution License (http://creativecommons.org/licenses/by/3.0), which permits unrestricted use, distribution, and reproduction in any medium, provided the original work is properly cited.

\section{INTRODUCTION}

The global burden of HCV infection is enormous mainly due to increased prevalence in the low

\section{Correspondence:}

Dr. Zahid Yasin Hashmi, FCPS.

Chairman,

Department of Gastroenterology,

Liver Center Faisalabad,

Faisalabad, Pakistan.

E-mail: profzyh@gmail.com

* Received for Publication:

* $1^{\text {st }}$ Revision Received:

* $2^{\text {nd }}$ Revision Received:

* Final Revision Accepted:
July 30, 2020

November 3, 2020

December 9, 2020

December 14, 2020 and middle-income countries. The infection rate is estimated to be $2.3 \%$ in the Eastern Mediterranean Region as per World Health Organization (WHO). ${ }^{1}$ Whereas globally it affects more than 71 million people. ${ }^{2}$ The precise burden of HCV in Pakistan is not known, however, as per careful estimates, over 7.8 million Pakistani population is affected by HCV and the seropositivity of the virus is still increasing. ${ }^{3}$ Unfortunately the interlinked high burden of unsterile needle use, blood transfusion 
in the absence of optimal donor blood screening practices, dental procedure and other surgeries performed by unqualified practitioners, infrequent sterilization and intravenous (IV) drug abuse attributes to this high burden of HCV infection in the Pakistani population. ${ }^{4}$

The therapeutic approach in relation to chronic HCV has always been challenging. Since 2011, DAAs have been approved for the management of HCV patients by the Food and Drug Administration (FDA) and European Medicines Agency (EMA) after conventional interferon. ${ }^{5}$ DAAs brought a revolution in the treatment of $\mathrm{HCV}$ and showed better compliance in terms of shorter duration of therapy, and a lesser number of adverse drug reactions reported as compared to Ribavirin and Interferon therapy. ${ }^{6}$ These DAAs have shown to achieve cure rates of over $90 \%$ regardless of previous treatment response, age, gender and ethnicity and are now part of preferred $\mathrm{HCV}$ treatment regimens as per international guidelines. ${ }^{1}$

Given this premise, now the next step in improving the $\mathrm{HCV}$ treatment protocol with DAAs is pharmacovigilance of the new drugs in order to improve the knowledge of drug safety. Different combinations of DAAs have been used in different groups of $\mathrm{HCV}$ patients worldwide and overall a lesser number of AEs are reported. However, now that the DAAs are prescribed increasingly around the globe, still few reports are available on the safety and occurrence of AEs based pharmacovigilance studies. Therefore, assessment of efficacy and safety through postmarketing studies is pivotal to make sure that DAAs are well tolerated with a better safety profile. Since much of the large data-based studies are conducted by high-income countries. Therefore, local evidence from Pakistan is scarce, we aim to report the safety profile of DAAs through this large multicentric study. The occurrence and spectrum of AEs, and severity of these events were assessed among chronic $\mathrm{HCV}$ patients receiving different combinations of DAAs in Pakistani Population. Such studies will lead us to generalize the data in terms of tolerability, evaluation of risk and safety profile of the local population.

\section{METHODS}

This multicenter, analytical cross-sectional study was conducted at six gastroenterology and hepatology centers including Liver Center
Faisalabad, Allama Iqbal Medical Institute and Liver Center DHQ Hospital Sialkot, Isra Hospital Hyderabad, Allied Hospital Faisalabad and Rehman Medical Institute Peshawar, between May 2018 and May 2019 after obtaining ethical approval from the PMA Ethics Committee (Reference Number: JA/758/LAE/67; Dated: $10^{\text {th }}$ April 2018). A total of 511 patients with chronic HCV receiving DAAs therapy were included in the study. Under primary inclusion, patients $\mathrm{HCV}$ of both genders with age $>18$ years were considered while the patients with co-infection such as hepatitis B and/or human immunodeficiency virus (HIV), were kept under exclusion together with pregnant and/or lactating females. The patients were recruited using convenience sampling technique, data confidentiality was ensured as per ICH GCP requirements and written informed consent was taken from each patient prior to inclusion in the study.

The data was collected using a pre-designed questionnaire inquiring patient demographics, relevant history, concomitant medication and ongoing treatment plan recommended for chronic $\mathrm{HCV}$. Moreover, the AEs associated with the prescribed treatment and its seriousness was also recorded as per the International Conference on Harmonization ( $\mathrm{ICH}$ ) classification and all reported AEs were presented by using the preferred term of Medical Dictionary for Regulatory Activities (MedDRA). The severity of medical events was assessed as per Karch and Lasagna classification ${ }^{7}$ which categorizes severity as minor when no antidote required nor therapy and/or prolongation of hospitalization needed, any change in drug therapy or any requirement of a specific treatment or hospitalization increased by at least one day was classified as moderate, whereas potentially lifethreatening events, causing permanent damage or need of intensive medical care were classified under severe and lethal that directly or indirectly contributes to the death of the patient. Data on outcome assessment were based on actions taken due to $\mathrm{AE}$, the outcome of the event (recovered or not), their suspected drugs as per physician observations along with the suspected dose.

The statistical analysis was carried out using SPSS version 20.0. Categorical variables were presented as frequencies \& percentages while continuous variables were described as mean and standard deviation. Independent sample t-test was applied to assess the mean age of patients with developing AEs. The Chi-square test was 
applied to estimate the AE occurrence rate among $\mathrm{HCV}$ patients receiving Ribavirin-based treatment and those with cirrhosis, where p-value $<0.05$ was considered as statistically significant.

\section{RESULTS}

A total of $511 \mathrm{HCV}$ patients receiving DAAs were included in the study of which $32 \%$ were males. Among the demographics, the mean age of the patients was found to be $43.5 \pm 11.7$ years, and the BMI was $25.3 \pm 5.1 \mathrm{~kg} / \mathrm{m}^{2} .87 .3 \%$ of these patients were given DAAs in combination with weight-based ribavirin. The patient's basic clinical and medical characteristics are given in Table-I.

A total of 419 AEs were reported (considering multiple reported AEs), out of which majority $(80.6 \%)$ patients experienced only one $\mathrm{AE}$, and $15.3 \%$ were reported having two AEs after receiving $\mathrm{HCV}$ treatment regime. The most common among them was pyrexia $(58.0 \%)$ followed by asthenia $(11.2 \%)$ and fatigue $(8.8 \%)$. Only 61 events were suspected from DAAs whereas the majority, 317 events were suspected with due to Ribavirin, five with concomitant therapy and remaining 36 were not classifiable. Out of these 61 AEs reported with DAAs, Sofosbuvir was administered in 54(88.6\%)

Table-I: Basic clinical and medical characteristics of the enrolled patients $(n=511)$.

\begin{tabular}{llc}
\hline Clinical and Medical Characteristics & $n(\%)$ \\
\hline Patient & Naive & $435(85.1)$ \\
History & Relapse & $54(10.6)$ \\
& Non-Responder & $22(4.3)$ \\
Cirrhosis & Non-cirrhotic & $348(68.1)$ \\
& Compensated cirrhosis & $43(8.4)$ \\
& Decompensated cirrhosis & $53(10.4)$ \\
Comorbidities & Noknown & $67(13.1)$ \\
& Diabetes Mellitus & $421(82.4)$ \\
& Hypertension & $44(8.6)$ \\
& CVD & $57(11.2)$ \\
Others & Lichen Planus & $6(1.1)$ \\
& Depression & $1(0.2)$ \\
& Anxiety & $3(0.5)$ \\
Treatment & SOF, DAC and RBV & $2(0.4)$ \\
Approach & SOF and RBV & $366(71.6)$ \\
& SOF and VLP & $55(10.76)$ \\
& SOF and DAC & $47(9.2)$ \\
& SOF, VLP and RBV & $18(3.5)$ \\
& & $25(4.9)$ \\
\hline
\end{tabular}

*SOF: Sofosbuvir, RBV: Ribavirin,

DAC: Daclatasvir, VLP: Velpatasvir.
Table-II: Adverse Events (AEs) as per MedDRA code among $\mathrm{HCV}$ patients taking medication.

\begin{tabular}{|c|c|}
\hline Reported Adverse Events & $n(\%)$ \\
\hline Blood and lymphatic system disorders & $14(3.3)$ \\
\hline Anaemia & $14(3.3)$ \\
\hline Cardiac disorders & $5(1.2)$ \\
\hline Palpitations & $5(1.2)$ \\
\hline Eye disorders & $1(0.2)$ \\
\hline Visual impairment & $1(0.2)$ \\
\hline Gastrointestinal disorders & $17(4.1)$ \\
\hline Abdominal discomfort & $1(0.2)$ \\
\hline Abdominal pain & $2(0.5)$ \\
\hline Abdominal pain upper & $5(1.2)$ \\
\hline Diarrhoea & $2(0.5)$ \\
\hline Gastroesophageal reflux disease & $2(0.5)$ \\
\hline Constipation & $1(0.2)$ \\
\hline Dyspepsia & $3(0.7)$ \\
\hline Vomiting & $1(0.2)$ \\
\hline $\begin{array}{l}\text { General disorders and administration } \\
\text { site conditions }\end{array}$ & $333(79.5)$ \\
\hline Pain & $6(1.4)$ \\
\hline Fatigue & $37(8.8)$ \\
\hline Pyrexia & $243(58.0)$ \\
\hline Asthenia & $47(11.2)$ \\
\hline Immune system disorders & $1(0.2)$ \\
\hline Asthma & $1(0.2)$ \\
\hline Investigations & $1(0.2)$ \\
\hline Weight decreased & $1(0.2)$ \\
\hline Metabolism and nutrition disorders & $1(0.2)$ \\
\hline Oedema peripheral & $1(0.2)$ \\
\hline $\begin{array}{l}\text { Musculoskeletal and connective } \\
\text { tissue disorders }\end{array}$ & 15(3.6) \\
\hline Arthralgia & $3(0.7)$ \\
\hline Muscle spasms & $7(1.7)$ \\
\hline Myalgia & $2(0.5)$ \\
\hline Pain in extremity & $3(0.7)$ \\
\hline Nervous system disorders & $19(4.5)$ \\
\hline Paraesthesia & $2(0.5)$ \\
\hline Dizziness & $1(0.2)$ \\
\hline Headache & $11(2.6)$ \\
\hline Amnesia & $2(0.5)$ \\
\hline Vertigo & $3(0.7)$ \\
\hline Psychiatric disorders & $8(1.9)$ \\
\hline Insomnia & $7(1.7)$ \\
\hline Depression & $1(0.2)$ \\
\hline Renal and urinary disorders & $1(0.2)$ \\
\hline Dysuria & $1(0.2)$ \\
\hline $\begin{array}{l}\text { Respiratory, thoracic and } \\
\text { mediastinal disorders }\end{array}$ & $1(0.2)$ \\
\hline Cough & $1(0.2)$ \\
\hline Skin and subcutaneous tissue disorders & $1(0.2)$ \\
\hline Pruritus & $1(0.2)$ \\
\hline Vascular disorders & $1(0.2)$ \\
\hline Epistaxis & $1(0.2)$ \\
\hline
\end{tabular}


cases, Daclatasvir in 6(9.8\%) and Velpatasvir was used in only $1(1.6 \%)$ case. Moreover, pyrexia, fatigue, headache, muscle spasm, asthenia, insomnia, palpitation, amnesia, abdominal pain upper, arthralgia, pain and vertigo were DAAs suspected AEs.

There was no serious AE reported as per the $\mathrm{ICH}$ classification. The severity distribution of AEs in 339 patients as per the Karch and Lasagna classification showed that $333(98.2 \%)$ patients were moderate inclusive of $325(97.6 \%)$ patients who received any corrective treatment, $4(1.2 \%)$ cases were of drug discontinuation, 3(0.9\%) required both dose adjustment and appropriate treatment and only one had dose adjustment issue. The other $6(1.8 \%)$ were minor in nature as no further management was required.

The use of ribavirin-based treatments significantly affected the AE occurrence ( $p$-value $<0.001$ ). The study results illustrated that the AE occurrence was five times higher among $\mathrm{HCV}$ patients receiving ribavirin-based treatment and cirrhotic $\mathrm{HCV}$ patients were two times more likely to have potential AEs as compared to the noncirrhotic $\mathrm{HCV}$ patients (Table-III).

\section{DISCUSSION}

The safety and efficacy of DAAs based therapeutic regime for $\mathrm{HCV}$ infection has now been established. ${ }^{8-10}$ Nevertheless, the chronic $\mathrm{HCV}$ infections are known to intensify the renal deterioration and hence the safety, efficacy and tolerability among $\mathrm{HCV}$ patients with certain degrees of renal impairment remain poorly understood and require further investigation. In this multicenter cross-sectional study, we assessed the safety profile, occurrence and severity of AEs among the $\mathrm{HCV}$ patients receiving different combinations of DAAs. The current findings suggest that DAAs are generally well-tolerated among the Pakistani population with no serious AEs reported. A local Pakistani study from Lahore confirmed the effectiveness of Sofosbuvir in combination with Ribavirin

Table-III: Occurrence of Adverse Events in relation to the administration of Ribavirin-based treatment and cirrhosis.

\begin{tabular}{lccc}
\hline Risk Factors & Adjusted OR* & $95 \%$ CI & $p$-value \\
\hline $\begin{array}{c}\text { Ribavirin-based } \\
\text { Treatment }\end{array}$ & 5.21 & $2.30-9.10$ & $<0.001$ \\
Cirrhosis Patient & 1.90 & $1.10-3.12$ & 0.019 \\
\hline
\end{tabular}

among highly infected HCV patients, as 34 out of 35 patients actively achieved Sustained Virologic Response (SVR) with no major sideeffects. ${ }^{11}$

Although being effective, it is essential to attain the real-world data verifying the safety and efficacy of this HCV treatment modality. ${ }^{12}$ Certain DAAs are not easily accessible due to high cost and hence its use might be limited in some states i.e. China restricts the use of DAAs as it is high-priced. However, adding to the real-world statistics, Zeng, $\mathrm{Hu}$ and their colleagues provided the safety and efficacy data concerning the use of different combination of DAAs for the treatment of $\mathrm{HCV} \cdot{ }^{13,14}$ In support the current study also established findings in favor of the safety of DAAs use i.e. among all the AEs experienced during $\mathrm{HCV}$ therapy with combinations of DAAs, there were no severe or lethal cases reported as per the severity classification. A recent pharmacovigilance study including the Egyptian population consuming Daclatasvir and Sofosbuvir in combinations with Ribavirin reported similar results displaying AEs in only $1.2 \%$ patients. ${ }^{15}$ Hence, the overall occurrence of AEs was greater in comparison to our reported rate i.e. $76 \%$ vs. $66 \%$. Another study assessed the efficacy and safety of DAAs among the German population and reported a similar burden of AEs to be $63 \%{ }^{16}$

The most commonly reported events were found to be pyrexia and fatigue. Similarly, a local review highlighting the changing treatment modalities and DAAs dynamics among HCV patients reported that headache, fatigue and nausea were the most common side-effects associated with the use of Paritaprevir and Dasabuvir/Ombitasvir and Ritonavir, common DAA combination and only $1 \%$ of the total affected patients are reported with treatment discontinuation. ${ }^{17}$ The most commonly reported AEs among Chinese patients receiving DAAs were nausea, diarrhea, acid regurgitation and bilirubin elevation in some patients. ${ }^{18}$ Another study conducted among Argentinian patients showed anemia to be one of the most common AE among DAAs receiving patients. A study conducted in Rawalpindi, Pakistan reported that patients receiving DAAs experienced generalized weakness and fatigue in $27.1 \%$ of the patients and fever in $8.9 \%$ of the patients as the most common AEs. ${ }^{19}$ 
It was found that the Ribavirin-based therapy was found to be significantly associated with the occurrence of AEs. A recently published review article also endorses our findings. It maintains that compared to Ribavirin based therapies, DAAs have better safety profile. ${ }^{6}$ Ribavirin use has been significantly linked to anemia, especially among decompensated and End-Stage Renal Disease (ESRD) patients, therefore it use in addition to DAA is not recommendable as it may be harmful. ${ }^{20,21}$ Furthermore, the cirrhotic incidences added up to the occurrence of AEs among the enrolled HCV patients $(p<0.05)$. It is evident that among $\mathrm{HCV}$ patients the presence of cirrhosis delays the treatment and negatively affects that therapeutic approach by significantly encouraging the occurrence of AEs. ${ }^{17}$ Additionally, the use of DAAs among $\mathrm{HCV}$ patients has been known to improve the glycemic control as per the results of a recent study conducted in Punjab. ${ }^{22}$ It was concluded that majority patients effectively achieved the optimal HbA1c levels and hence displayed improved Glycemic Control. ${ }^{22}$ Whereas, a local study has also provided data against the evident efficacy outcomes, suggesting that the Hepatocellular Carcinoma (HCC) was frequent among HCV patients treated with DAAs. ${ }^{23}$

Limitations of the study: Although the study findings can begeneralized to the whole population as it was multicenter including a large sample size but long-term follow-ups could enhance the knowledge regarding future implications of DAAs among the Pakistani population. Due to the design limitations, potential sources of bias can be information, sampling and interviewer bias and other limitation could be causality assessment of reported cases.

\section{CONCLUSION}

DAAs are generally well-tolerated among the local Pakistani population as no serious AEs were reported. Among all AEs, experienced during HCV therapy, there was no severe or lethal cases reported as per the severity classification. The most commonly reported events with DAAs were pyrexia and fatigue. Additionally, HCV patients received Ribavirin with DAAs therapy as well as those who were cirrhotic had significant AEs risk. Hence it is recommended that such patients should be closely monitored.
Acknowledgement: The authors are thankful to the Getz Pharma for providing a research grant and its Medical Affairs department for their assistance in statistical analysis, manuscript review and publication planning.

Conflicts of Interest: The author(s) declare no conflicts of interest.

Grant Support \& Financial Disclosures: The authors did not get financial support from any organization for the conduct of the study.

\section{REFERENCES}

1. Organization WH. Hepatitis C 2018 [updated 18 July 201823 June 2018]. Available from: https://www.who. int/news-room/fact-sheets/detail/hepatitis-c.

2. Liaw Y-F, mcmahon B. Viral Hepatitis, B and C: lift the global burden. S. Afr. Gastroenterol. Rev. 2018;16(1):36.

3. Mehmood S, Raza H, Abid F, Saeed N, Rehan HM, Javed S, Khan MS. National prevalence rate of hepatitis B and C in Pakistan and its risk factors. Int. J. Public Health. 2019:1-4. doi: 10.1007/s10389-019-01119-8.

4. Khaliq S, Raza S. Current status of direct acting antiviral agents against hepatitis $\mathrm{C}$ virus infection in Pakistan. Medicina. 2018;54(5):80 doi: 10.3390/medicina54050080.

5. Maan R, van der Meer AJ. Recent advances in managing chronic HCV infection: focus on therapy in patients with severe liver disease. F1000Research. 2016;5:F1000 Faculty Rev-367. doi: 10.12688/f1000research.7399.1

6. Scavone C, Sportiello L, Rafaniello C, Mascolo A, Sessa $\mathrm{M}$, Rossi F, et al. New era in treatment options of chronic hepatitis C: focus on safety of new direct-acting antivirals (daas). Expert Opin. Drug Saf. 2016; 15(sup2):85-100. doi: 10.1080/14740338.2016.1221396

7. Ross SB, Wu P, Atique A, Papillon-Ferland L, Tamblyn R, Lee $T$ et al. Adverse Drug Events in Older Adults: Review of Adjudication Methods in Deprescribing Studies. J Am Geriatr Soc. 2020. doi: 10.1111/jgs.16382

8. Khan M, Khan S, Haider S, Jalil F, Jamal M, Ahmad A. Prevalence and Risk Factors of Hepatitis C Virus (HCV) in Tehsil Batkhela District Malakand, KPK, Pakistan. IJCRR. 2018; 9(06):20251-20256. doi: 10.15520/ ijcrr/2018/9/06/525

9. Lim AG, Qureshi H, Mahmood H, Hamid S, Davies CF, Trickey A, et al. Curbing the hepatitis $C$ virus epidemic in Pakistan: the impact of scaling up treatment and prevention for achieving elimination. Int J Epidemiol. 2018;47(2):550-560. doi: 10.1093/ije/dyx270

10. Saleem S, Ali A, Khubaib B, Akram M, Fatima Z, Idrees M. Genetic diversity of Hepatitis C Virus in Pakistan using Next Generation Sequencing. J Clin Virol. 2018;108:26-31. doi: 10.1016/j.jcv.2018.09.001

11. Hashmi MA, Cheema HA. Effectiveness and Safety of Sofosbuvir in Treatment-NäiveChildren with Hepatitis C Infection. J Coll Physicians Surg Pak.2017; 27(7):423-426.

12. Flisiak R, Pogorzelska J, Flisiak-Jackiewicz M. Hepatitis C: efficacy and safety in real life. Liver Int. 2017;37:26-32. doi: 10.1111/liv.13293

13. Zeng QL, Xu GH, Zhang JY, Li W, Zhang DW, Li ZQ, et al. Generic ledipasvir-sofosbuvir for patients with chronic hepatitis C: A real-life observational study. J Hepatology. 2017; 66(6):1123-1129. doi: 10.1016/j.jhep.2017.01.025 
14. Hu C, Yuan G, Liu J, Huang H, Ren Y, Li Y, et al. Sofosbuvir-based therapies for patients with Hepatitis $\mathrm{C}$ virus infection: real-world experience in China. Can J Gastroenterology Hepatol. 2018; Article ID 3908767. doi: $10.1155 / 2018 / 3908767$

15. Ahmed EI, Abdel Wahed WY, Hassan EA, Ahmed TI. Study of Adverse Drug Effects of Direct-Acting Antivirals for Chronic HCV Infection at Fayoum Governorate, Egypt - A Pharmacovigilance Study. Curr Drug Saf. 2018;13(3):187195. doi: 10.2174/1574886313666180716111529

16. Vermehren J, Peiffer KH, Welsch C, Grammatikos G, Welker MW, Weiler N, et al. The efficacy and safety of direct acting antiviral treatment and clinical significance of drugdrug interactions in elderly patients with chronic hepatitis C virus infection. Aliment Pharm Ther. 2016;44(8):856-865. doi: 10.1111/apt.13769

17. Umar M, Akhter TS. New direct acting antiviral agents for the treatment of hepatitis C: 2016 and beyond. J Coll Physicians Surg Pak. 2016; 26(10):843-850.

18. Zhang J, Sun W, Lin J, Tian Y, Ma L, Zhang L, et al. Long-term follow-up of HCV infected kidney transplant recipients receiving direct-acting antiviral agents: a singlecenter experience in China. BMC Inf Diseases. 2019;19(1): Article ID 645.

19. Akhter TS, Umar M, Aslam F, Nisar G, Naseer A, Ahmad S, et al. Sofosbuvir for the treatment of hepatitis $C$ genotype 3 infected patients in Pakistan. J Ayub Med Coll Abbottabad. 2017;28(4 Sup):884-889.

20. Lawitz E, Sulkowski MS, Ghalib R, Rodriguez-Torres M, Younossi ZM, Corregidor A, et al. Simeprevir plus sofosbuvir, with or without ribavirin, to treat chronic infection with hepatitis $\mathrm{C}$ virus genotype 1 in non-responders to pegylated interferon and ribavirin and treatment-naive patients: the COSMOS randomised study. Lancet. 2014;384(9956):1756-1765. doi: 10.1016/S0140-6736(14)61036-9
21. Bourliere M, Benali S, Ansaldi C, Le Folgoc G, Riso A, Lecomte L. Optimal therapy of genotype-2 chronic hepatitis C: What's new? Liver Int. 2015; 35(Suppl 1):21-26. doi: 10.1111/liv.12711

22. Nazar T, Aziz B, Ghias M. Treatment Response of Direct Acting Antiviral Agents on Glycemic Control in Diabetic Patients with Chronic Hepatitis C. PJMHS. 2019;13(1):169-172.

23. Aziz B, Nazar T, Akhlaq S. The frequency of occurrence of Hepatocellular Carcinoma after direct antiviral therapy in Hepatitis C virus patients. PaK J Med Sci. 2019; 35(1):101105. doi: $10.12669 /$ pjms.35.1.109

\section{Authors Contribution:}

ZYH, MQZ, AB, MA, NA, MR, JBB: Are responsible for the concept and study design.

ZYH, MQZ, AB, MA, NA: Contributed to the data collection and literature review.

MR, JBB: Are responsible for data analysis and interpretation and drafting of the manuscript.

ZYH, MQZ, AB, MA, NA, MR, JBB: Contributed to the critical review, revision and final approval of the study.

All the authors are equally responsible and accountable for the accuracy and integrity of the work.
Authors:

1. Zahid Yasin Hashmi, FCPS

Liver Center Faisalabad, Pakistan.

2. Muhammad Qasim Zia, FCPS

Allama lqbal Memorial Teaching Hospital, Sialkot, Pakistan.

3. Akram Bajwa, Ph.D. Liaquat University of Medical \& Health Sciences, Hyderabad, Pakistan.

4. Maqsood Ahmed, FCPS Allied Hospital Faisalabad, Pakistan.

5. Naveed Anwer, MRCP Rehman Medical Institute Peshawar, Pakistan.

6. Mahwish Raza, Pharm-D Shaheed Zulfikar Ali Bhutto Institute of Science and Technology, Karachi, Pakistan.

7. Jaffer Bin Baqar, MSc. University of Karachi, Karachi, Pakistan. 